EDUCATIONAL

- RESOURCE

Volume 11 Issue 12019

DOI: 10.21315/eimj2019.11.1.6

ARTICLE INFO

Submitted: 02-10-2018

Accepted: 06-02-2019

Online: 29-03-2019

\title{
Should I Tell Her The Truth?
}

\author{
Lili Husniati Yaacob
}

Department of Family Medicine, School of Medical Sciences, Universiti Sains Malaysia, Kelantan, MALAYSIA

To cite this article: Yaacob LH. Should I tell her the truth? Education in Medicine Journal. 2019;11(1):49-52. https://doi.org/10.21315/eimj2019.11.1.6

To link to this article: https://doi.org/10.21315/eimj2019.11.1.6

\section{ABSTRACT}

This case illustrates the issue of truth-telling about a diagnosis of a potentially terminal illness. A family member of an elderly patient requests that the treating doctor does not disclose the diagnosis to the mother for fear that it will distress her and cause her anxiety. The challenge of the treating doctor is how to deal with this in a professional and ethical manner.

Keywords: Truth-telling, Autonomy, Cancer, Culture

Dr. Lili Husniati Yaacob, Department of Family Medicine, School of Medical Sciences, Universiti Sains Malaysia, 16150 Kubang Kerian, Kelantan, Malaysia | E-mail: husniati@ usm.my

\section{INTRODUCTION}

Truth-telling or veracity is one of the fundamental elements of medical ethics. An important part of a doctor's responsibilities is informing the patient regarding their illness and its subsequent management. Doctors are expected to share patients' medical information with them in a truthful manner as possible. This is necessary in helping to build trust with their patient and in establishing a constructive working relationship. However, there are instances when doctors have to make a decision about whether telling patients the whole truth about their diagnoses would, in the end, benefit their patient or not. When disclosing information to their patients, doctors must also decide how particular information is to be told, keeping in mind that their patients may have preferences in terms of how much information they want to know and how they wish that information to be delivered.
This case illustrates the difficulty doctors face when making a decision regarding breaking the bad news to a patient without the approval of the family members.

\section{CASE SUMMARY}

Mrs. Maryam is a 75-year old woman who presented with a history of abdominal discomfort and jaundice for the past three months. She had no past medical problems and was otherwise well. Mrs. Maryam lived with her son and his family; her husband had passed away several years ago. During the visit, she was accompanied by her son. During the consultation, she appeared to be anxious and relied on her son to answer most of the questions regarding her condition.

On examination, she was jaundiced with tender, palpable liver measuring $14 \mathrm{~cm}$ and presence of ascites. Bedside ultrasound 
was performed showing an enlarged liver with multiple nodules measuring $2-3 \mathrm{~cm}$. Blood investigations for liver function test and hepatitis $\mathrm{B}$ and $\mathrm{C}$ screening was done. The differential diagnosis at the time was liver cancer. The son was very concerned about his mother's condition and was very protective of her. He expressed his wishes for the doctor not to inform his mother of her diagnosis since it would alarm her and caused her further distress. He claimed that his mother was easily anxious and always had difficulty handling bad news. He was worried that the news regarding the diagnosis would cause his mother to become more worried and more unwell. $\mathrm{He}$ also claimed that his mother had always told him that she hated hospitals, and he said that she would likely not agree to be admitted for further management. He claimed that he had discussed the issue with other family members, and they all agreed that their mother need not be told of her diagnosis. They had also decided not to pursue any treatment due to their mother's age. Their intention in coming to the hospital was only to get medication for the abdominal discomfort.

\section{ETHICAL ISSUE DISCUSSION}

\section{Medical Indication}

In Mrs. Maryam's case, given the clinical and ultrasound findings it is most likely that her cancer is at least in the intermediate stage based on Barcelona Clinic Liver Cancer (BCLC) staging system for hepatocellular carcinoma (HCC) (1). In order to properly diagnose the disease, a CT scan or MRI and/or biopsy are required. In order to proceed with the investigations, Mrs. Maryam needs to give consent to them and this requires that she be fully informed of the possible diagnosis and its subsequent management.

It is important to perform disease staging to decide on further management and prognostication of cancer. Surgical resection, local ablation therapies, and liver transplantation are regarded as potentially curative treatment modalities depending on the size and number of tumors (2). It is also important to note that the patient is elderly, as this affects her prognosis. Of people aged 75 and over who are diagnosed with liver cancer, only around 5\% survive their cancer for 5 years or more (3). Another medical issue to consider is the patient's mental capacity.

It is important that the treating doctor assess Mrs. Maryam's mental health to ensure that she would be able to understand her diagnosis and make sound decisions regarding it. This can be done objectively by performing mental state examination. All of these factors should be considered when dealing with this case.

\section{Patients' Preference}

It is difficult to determine the patient's preference without having a frank discussion with her. According to the son, his mother hates hospital and would likely refuse to be admitted for further management. However, the treating doctor needs to delve deeper on this issue and find out what is the patient's expectation and preference in the management of her illness. This can be done with or without the patient's knowledge about her illness.

\section{Quality of Life}

Based on the guidelines from the American Association for the Study of Liver Diseases (AASLD), one of the options for the management of HCC in the intermediate stage is palliative treatment with transarterial chemoembolization and sorafenib (1). The treatment should improve the patient's symptoms, namely the abdominal discomfort. This will improve the patient's quality of life.

However, Mrs. Maryam needs to be aware of the possible diagnosis and she must consent to the necessary investigation before any treatment can be instituted. Without 
full or proper knowledge of her disease, she might not be given the best possible treatment. She might just be prescribed a pain killer and discharged home without further management.

\section{Contextual Features}

Several factors in the context of this case are significant. While the patient has a legal and ethical right to know about her diagnosis, the doctor was conflicted since it appears to be culturally acceptable for children to decide on their parents' health issue, especially when the parents are very elderly.

Further discussion with the son revealed that the patient has been in the care of the son for many years and she has often turned to the son to make decisions for her. Should the doctor just be truthful to the patient and inform her of what is going on without considering the wishes of her children? After all, it is the patient's right to make the decision and she is legally and mentally competent to do so. On the other hand, should the doctor not also consider the wishes of the son who is only thinking about the welfare of his mother?

\section{DISCUSSION}

Collusion is a secret agreement between two parties to deceive, mislead, or defraud others of their legal rights. In this case, the family requests the doctor to collude with them by withholding the diagnosis of the illness from their mother for the perceived benefit of the mother. The patient's right is her autonomy to make decisions regarding her care.

Autonomy is defined as the capacity to make an informed, un-coerced decision. Patient autonomy lies at the foundation of Western medical ethics; however, in the East, this principle is viewed differently. In Western societies, autonomy is an individual right, whereas our Asian community regards the family as a unit and treats familial autonomy is more important than individual autonomy (4). Therefore a "shared autonomy" between the patient and their family members may be more appropriate in the setting of this case. Doctors need to be sensitive to the cultural issue that play a role in their patient's decision-making.

The best way to go about this is to ask the patient how she wants to proceed and whether she wants her family members to be involved in the decision-making process or not. The patient needs to be assessed whether she wants to know about the possible diagnosis and its subsequent management, or whether she wants her family members to be involved in this.

If the patient decides she wants to know, then the doctor is not only professionally required but also ethically obliged to be truthful to her. She needs to be informed regarding the risks and benefits of further investigation and treatment of her condition so she can make an informed decision.

If the family insisted that the doctor withhold information from their mother, the doctor must explain to them that it is their mother's right to know about the truth. Knowledge about an illness, especially potentially terminal illness, is important for the patient.

Truth-telling will help the patient better make sense of having and managing their illness (5). There are also a lot of things that patient may need to settle while they are fairly healthy such as legal and financial issue and having a full understanding of their condition will help them with this. It can also be harmful to abstain a vital life ending information to the patient as it might affect their overall approach to her illness. The patient may not be willing to accept any helpful therapy (whether life-saving or for symptomatic relief) if she does not know the full circumstances of her illness.

The family members also need to be reassured that whatever information that is shared by the doctor will be shared in a tactful manner and how much is shared will be in accordance with the patient's wishes. 
What if the children still refuse and wish the mother to be kept in the dark? The role of patient's surrogate, in this case the children, to make a decision in the presence of a competent patient is ethically invalid. This is why it is important for the treating doctor to assess the patient's mental capacity and make sure she is of sound mind and capable to make legal decisions.

Another approach to settle this conflict is by having a family meeting. An honest and open discussion can be had among family members. This should be done in a tactful manner with empathy and good communication.

In the end, it is up to the patient to make the decision about whether she wants to be told about her diagnosis and to decide on the subsequent management. However, "shared autonomy" with the family members is an appropriate approach based on the cultural context.

\section{CONCLUSION}

As a conclusion, truth-telling is an important element in the therapeutic relationship and should be upheld to the best of our ability. However, it is also important to consider cultural norms in patient's management to ensure the best outcome for all.

\section{REFERENCES}

1. Bruix J, Sherman M. Management of hepatocellular carcinoma: an update. Hepatology. 2011;53(3):1020-2. https://doi. org/10.1002/hep.24199

2. Livraghi $\mathrm{T}$, Mäkisalo $\mathrm{H}$, Line $\mathrm{PD}$. Treatment options in hepatocellular carcinoma today. Scand J Surg. 2011;100(1):22-9. https://doi.org/10.1177/ 145749691110000105

3. Office for National Statistics. Cancer survival in England: patients diagnosed between 2011 and 2015 and followed up to 2016 (National Statistics). 29 June 2017 [cited 6 January 2019]. Available from: https://www.ons.gov. uk/peoplepopulationand community/ healthandsocialcare/conditionsanddiseases/ bulletins/cancersurvivalinengland/adultstage atdiagnosisandchildhoodpatientsfollowedupt o2016\#cancer-survival-in-england-patientsdiagnosed-between-2011-and-2015-andfollowed-up-to-2016-national-statistics

4. Tai MC-T. Western or Eastern principles in globalized bioethics? An Asian perspective view. Tzu Chi Medical Journal. 2013;25(1):64-7. https://doi.org/10.1016/j. tcmj.2012.05.004

5. Surbone, A. Telling the truth to patients with cancer: what is the truth? Lancet Oncol. 2006; 7:944-50. https://doi.org/10.1016/ S1470-2045(06)70941-X 